\title{
Research on the Activation Energy of the Crystallization Process for the Amorphous Solids in Blast Furnace Slag
}

\author{
WANG Hai-feng ${ }^{1,}$ a, LIU Yang ${ }^{1}$, QI Yuan-hong ${ }^{1}$, YAN Ding-liu ${ }^{1}$ \\ ${ }^{1}$ State Key Laboratory of Advanced Steel Processing and Products, Central Iron \& Steel Research \\ Institute, Beijing, China 100081 \\ awhf@cisri,com
}

Keywords: Dry Slag Granulation Technology; Kinetics of Crystallization; Activation Energy of Crystallization; X-ray Diffraction

Abstract. The application of BF slag depends on the content of amorphous solids in the slag after treatment. The research on the activation energy of crystallization of amorphous solids in BF slag is the foundation to find out the reasonable cooling speed during dry granulation of molten slag. The BF slag of steel plant A taken as a typical example, quantitive X-ray diffraction method for analyzing the content of amorphous solids in the slag was used in this research. The kinetics of crystallization of amorphous solids in BF slag was studied. The activation energy of crystallization of amorphous solids in BF slag(E) was $108.90 \mathrm{~kJ} / \mathrm{mol}$.

\section{Introduction}

Usually a large amount of blast furnace $(\mathrm{BF})$ slag is produced every year and most of them is treated with water in China. Since the composition of BF slag is similar to Portland cement, the major compounds in the molten BF slag become amorphous with chemical energy in the rapid cooling process and the content of amorphous solids after granulation must be over $95 \%$, it can be further used as the raw material to produce Portland cement ${ }^{[1-3]}$. China is short of water seriously. The granulation of BF slag with water quenching has many disadvantages, such as high water consumption and difficulty in heat recycling. So developing a new dry granulation technology to treat the BF slag is very important. The applicability of BF slag directly depends on the content of amorphous solids in the slag after treatment ${ }^{[4-6]}$. The research on the activation energy of crystallization of amorphous solids in $\mathrm{BF}$ slag is the foundation to find out the reasonable cooling speed during dry granulation of molten slag. So it is of theoretical and practical significance to be analyzed.

\section{Theoretical analysis}

\section{Reaction order of crystallization}

The amorphous solids in BF slag would be transformed into crystallization under the condition of heating, which is: Amorphous solids $\stackrel{\text { heating }}{\longrightarrow}$ Crystallization

According to the law of mass action ${ }^{[1]}$ : at a certain temperature, the reaction rate of crystallization was proportional to the $\mathrm{n}^{\text {th }}$ power of the concentration of amorphous solids (reactant), which is:

$$
v_{C}=-\frac{d C}{d t}=k C^{n}
$$

where: $v_{\mathrm{C}}$ is the reaction rate of crystallization $(1 / \mathrm{s}), C$ is the mass percentage of amorphous solids in $\mathrm{BF}$ slag(1), $t$ is the reaction time(s), $k$ is the reaction rate constant of crystallization of amorphous solids in $\mathrm{BF} \operatorname{slag}(1 / \mathrm{s}), n$ is the reaction order.

The zero order reaction was taken as an example: $-\frac{d C}{d t}=k C^{0}=k$

When $\mathrm{t}=0, \mathrm{C}=\mathrm{C}_{0}=100 \%$, where: $\mathrm{C}_{0}$ is the mass percentage of amorphous solids in BF slag at the beginning as $100 \%$. 
When $\mathrm{t}=\mathrm{t}, \mathrm{C}=\mathrm{C}_{0}-\varphi$, where: $\varphi$ is the crystallization rate of amorphous solids in $\mathrm{BF}$ slag at 'time $\mathrm{t}$ '.

From 0 to t, Eq.(2) was integrated as Eq.(3): $\quad \int_{C_{0}}^{C}(-d C)=\int_{0}^{t} k d t$

So, $C_{0}-C=k t$

$$
\varphi=\mathrm{kt}
$$

)

In the same way, the differential and integral formulae of reaction velocity equations of the crystallization reactions for the first and second order were $\varphi=\ln \frac{1}{1-\varphi}$ and $\varphi=\frac{\varphi}{1-\varphi}$. The order of the crystallization reaction of amorphous solids in BF slag was determined by linear-fitting method. The amorphous slag was heated at different temperatures as 1073K, 1173K, 1273K, 1373K and 1473K for different time and the crystallization rates of amorphous solids in BF slag could be obtained. The time(t) was taken as the abscissa and the crystallization rate of amorphous solids in $\operatorname{BF} \operatorname{slag}(\varphi)$ was taken as the ordinate. The relationship between $t$ and $\varphi$ was calculated. In the same way, the relationship between $\mathrm{t}$ and $\ln \frac{1}{1-\varphi}$ or $\frac{\varphi}{1-\varphi}$ was calculated, separately. If the relationship between $\mathrm{t}$ and $\varphi$ is linear under the $1073 \mathrm{~K}$, it is of zero order of the crystallization reaction of amorphous solids in BF slag at $1073 \mathrm{~K}$, and so on.

\section{Activation energy of crystallization}

According to the Arrhenius equation ${ }^{[7]}: \quad \frac{d \ln k}{d T}=\frac{E}{R T^{2}}$

where: $k$ is defined as Eq.(1), $T$ is the temperature(K), $E$ is the activation energy of crystallization of amorphous solids in BF slag $(\mathrm{J} / \mathrm{mol}), R$ is the Avogadro's constant, $8.314 \mathrm{~J} / \mathrm{mol} \cdot \mathrm{K}$.

Generally, E would not be changed with temperature. Eq.(6) was integrated as Eq.(7):

$$
\ln \mathrm{k}=-\frac{\mathrm{E}}{\mathrm{RT}}+\mathrm{A}
$$

\section{Required cooling rate of BF slag at different temperatures}

The Eq. (7) was rewritten as Eq.(8). $k=k_{0} \exp \left(-\frac{E}{R T}\right)$

The logarithmic calculation was taken on Eq. (8). $-\frac{d \ln (1-\varphi)}{d t}=k$

So, $-d \ln (1-\varphi)=k_{0} \exp \left(-\frac{E}{R T}\right) d t$

For, $T=T_{0}-v t$

where: $T$ is the temperature of the BF slag after time $\mathrm{t}(\mathrm{K}), T_{0}$ is the origin temperature of the BF $\operatorname{slag}(\mathrm{K}), v$ is the cooling speed $(\mathrm{K} / \mathrm{s})$, and $t$ is the time $(\mathrm{s})$.

$t=\frac{T_{0}-T}{v}$

Eq.(12) was taken into Eq.(10), $-d \ln (1-\varphi)=k_{0} \exp \left(-\frac{E}{R T}\right) d \frac{T_{0}-T}{v}$

$d \ln (1-\varphi)=\frac{k_{0}}{v} \exp \left(-\frac{E}{R T}\right) d T$

The time $\mathrm{t}$ was from the origin time to the cooling temperature, $\varphi$ was from 0 to 0.05 , and $\mathrm{T}$ was from $1723 \mathrm{~K}$ to $973 \mathrm{~K}$, 


$$
\begin{aligned}
& \int_{0}^{0.05} d \ln (1-\varphi)=\int_{T_{0}}^{T} \frac{k_{0}}{v} \exp \left(-\frac{E}{R T}\right) d T \\
& \text { So, } v=-7014.4 \int_{T_{0}}^{T} \exp \left(-\frac{E}{R T}\right) d T
\end{aligned}
$$

\section{Experiments}

\section{Materials}

The BF slag of steel plant A was dealt with open cycle process( $\mathrm{OCP})$. The granulated BF slag were almost amorphous solids as $100 \%$ amorphous solids sample. The component of the slag were $w(\mathrm{CaO})$ $38.2 \%, w\left(\mathrm{SiO}_{2}\right) 35.7 \%, w\left(\mathrm{Al}_{2} \mathrm{O}_{3}\right) 16.3 \%, w(\mathrm{MgO}) 8.3 \%, w(\mathrm{FeO}) 0.4 \%, w(\mathrm{~S}) 1.0 \%$ and $R=1.070$.

\section{Methods}

(1) The $10 \mathrm{~g}$ BF slag by water quenched with $100 \%$ amorphous solids were put into the crucible as the thin layer. The entire sample could be in contact with the air. The furnace was heated to $1073 \mathrm{~K}$ and held. The sample with the crucible was placed into the heating furnace and the furnace door was closed. After a certain time $t_{1}$, the crucible was taken out and the sample was cooled to $293 \mathrm{~K}$ in the air quickly.

(2) The sample was milled and passed through a 200 mesh sieve and analyzed by the X-ray diffraction instrument. The test conditions were the $\mathrm{Cu}$ target, $40 \mathrm{kV}, 40 \mathrm{~mA}$, and the scanning speed of 2 degree/min. The X-ray diffraction pattern of the sample was got. The content of amorphous solids in BF slag was quantitatively analyzed by X-ray diffraction method ${ }^{[8,9]}$.

(3) The above experimental steps were repeated at 1073K. The samples were heated at different time as $t_{2}, t_{3}, \ldots$ and etc, respectively. The crystallization rate and time of the amorphous solids in BF slag at $1073 \mathrm{~K}$ were obtained.

(4) The experiments were repeated. The samples were heated at different temperature as $1173 \mathrm{~K}$, $1273 \mathrm{~K}, 1373 \mathrm{~K}$ and $1473 \mathrm{~K}$, and at different time as $\mathrm{t}_{1}, \mathrm{t}_{2}, \mathrm{t}_{3}, \ldots$ and etc, respectively. The crystallization rate and time of the amorphous solids in BF slag at 1173K, 1273K, $1373 \mathrm{~K}$ and 1473K were got.

\section{Results and discussion}

Respectively, the X-ray diffraction pattern of the BF slag heated and held for different time at $1073 \mathrm{~K}, 1173 \mathrm{~K}, 1273 \mathrm{~K}, 1373 \mathrm{~K}$ and $1473 \mathrm{~K}$ were calculated. The contents of amorphous solids in BF slag were quantitatively analyzed by X-ray diffraction method ${ }^{[10-12]}$. The crystallization reaction was of first order, and the reaction rate constant of crystallization of amorphous solids in BF slag (k) was calculated.

The reaction rate constant of crystallization of amorphous solids in BF slag at temperature $1073 \mathrm{~K}$ to $1473 \mathrm{~K}$ were calculated by the same method. The reciprocal of temperature $(1 / \mathrm{T})$ was taken as the abscissa and the logarithm of the crystallization rate(lnk) was taken as the ordinate(Fig.1). The relationship between 1/T and lnk was calculated as Eq.(7).

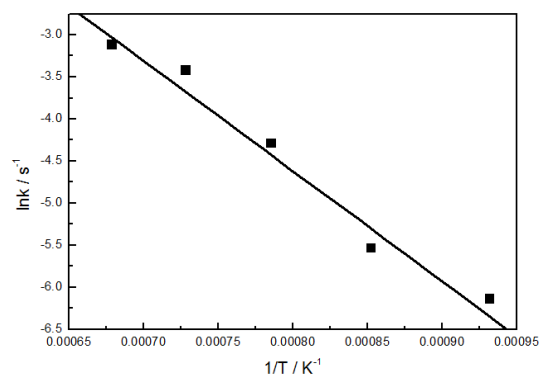

Figure 1 Diagram for activation energy of crystallization calculation 


$$
\operatorname{lnk}=-13097.95 / \mathrm{T}+5.86
$$

The slope is -13097.95 with standard error 0.25 and the intercept is 5.86 with standard error 0.89 .

Eq.(17) was compared with Eq.(7): $\quad-\frac{E}{R}=-13097.95$

Therefore, the activation energy of crystallization of amorphous solids in BF slag(E) was 108.90 $\mathrm{kJ} / \mathrm{mol}$ with the relative standard error and the constant(A) was 5.86.

\section{Conclusions}

The results showed that:

(1) The crystallization of amorphous solids in BF slag was of first order reaction. The relationship among the crystallization rate of amorphous solids in $\mathrm{BF} \operatorname{slag}(\varphi)$, the reaction rate constant of crystallization of amorphous solids in BF slag $(\mathrm{k})$ and the reaction time $(\mathrm{t})$ was $\ln \frac{1}{1-\varphi}=k t$. (2) The relationship between the reaction rate constant of crystallization of amorphous solids in BF $\operatorname{slag}(\mathrm{k})$ and the temperature $(\mathrm{T})$ was $\operatorname{lnk}=-13097.95 / \mathrm{T}+5.86$. The activation energy of crystallization of amorphous solids in BF slag(E) was $108.90 \mathrm{~kJ} / \mathrm{mol}$. The required cooling rate for BF slag from $1723 \mathrm{~K}$ to $973 \mathrm{~K}$ was more than $100 \mathrm{~K} / \mathrm{s}$.

(3) Based on the study, the process and equipment for the dry slag granulation (DSG) technology was desired.

\section{References}

[1] Q. T. Fang. Introduction of blast furnace slag powder in cement production application [J]. Industrial b, 2016 (7) : 00173-00174.

[2] H. Li, J. Xing, Y.L. Zhao, et al. Experiment of new cementing material based on blast furnace slag [J]. Journal of nonferrous metals (mine), 2016, 68 (6).

[3] P. Colombo, G. Brusatin, E. Bernardo, et al. Inertization and reuse of waste materials by vitrification and fabrication of glass-based products $[\mathrm{J}]$. Current opinion in solid state \& materials science, 2003, 7(3):225-239.

[4] B. Lin, H. Wang, X. Zhu, et al. Crystallization properties of Chongqing steel blast furnace slag under different cooling rate $[\mathrm{C}]$. Higher education institute engineering thermal physics professional committee of the national academic conference proceedings [A]. 2015.

[5] C. Fredericci, E.D. Zanotto, E.C. Ziemath. Crystallization mechanism and properties of a blast furnace slag glass [J]. Journal of Non-Crystalline Solids, 2000, 273(1-3):64-75.

[6] Y.C. Wang, W.W. Yu, J.L. Zhang, et al. Crystallization kinetics and microstructure of glass-ceramics prepared from Baotou steel blast furnace slag[J]. Cailiao Rechuli Xuebao/transactions of Materials \& Heat Treatment, 2014, 35(1):88-93.

[7] Y.J. Liang. Physical chemistry. Beijing: metallurgical industry press. 1983:238.

[8] H.F. Wang, C.X. Zhang, Y.H. Qi. Quantitative analysis of non-crystalline and crystalline solids in blast furnace slag. Journal of iron and steel research, international, 2011, 18(1):8-10.

[9] H.F. Wang, C.X. Zhang, Y.H. Qi. Comparation of quantitative analysis method for non-crystalline solids in blast furnace slag [J]. Journal of iron and steel research, 2010, 22(11):60-62.

[10] S.F. Liao, Y.X. Chen, H.J. Li. Application of the quantitative X ray diffraction analysis in the clinker analysis [J]. Research and application of building materials. 2004, 6:11-13.

[11]J.Y. Qi. X-ray structure analysis [M]. Shanghai: tongji university press, 2003.

[12] G.D. Zhang. Materials research and testing methods [M]. Beijing: metallurgical industry press. 2002:117. 